\title{
Amelioration of Hyperglycemia and Dyslipidemia in Alloxan-Induced Diabetic Rats Using Citrulluslanatus and Persea Americana
}

\author{
Ukpabi.C.F ${ }^{1}$ \\ Minaseidiema.R. ${ }^{2}$ \\ Anyaogu.E.J ${ }^{3}$ \\ Njoku.C.I ${ }^{4}$ (D) \\ Esihe.T.E ${ }^{5}$
}

\section{(iD)}

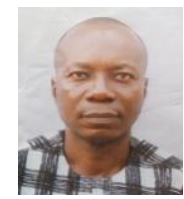

( Corresponding Author)

1,2,s,4 Department of Biochemistry, Abia State Polytechnic, Aba, Nigeria.

'Email:ukpabichibueze@yahoo.com

${ }^{5}$ Department of Chemistry, Abia State Polytechnic, Aba, Nigeria.

\section{Abstract}

Dyslipidemia has been observed to play an integral role in the pathogenesis of micro and macrovascular complications in diabetes mellitus patients. The complications were assessed via atherogenic index (AI), Coronary risk index (CRI) and Cardiovascular risk index (CVRI).The study was to investigate the amelioration of hyperglycemia and dyslipidemia in alloxan induced rats using watermelon and avocado seeds. A total of Forty rats were divided into eight groups of 5 rats accordingly. Diabetes was induced with a single dose of alloxan $(100 \mathrm{mg} / \mathrm{kg})$ body weight and serum glucose was taken $72 \mathrm{~h}$ after induction of confirm diabetes. Amelioration of hyperglycemia and dyslipidemia started on the $6^{\text {th }}$ and $9^{\text {th }}$ day of the experiment respectively. The result obtained from the phytochemical analysis showed that the aqueous extract of Citrulluslanatus and Persea Americana gave positive reactions for Alkaliods, tannins, flavonoids and saponins. The data showed that Alloxan caused significant increase in Glucose, TC, TGs and LDL in the untreated diabetic rats. On the other hand HDL was significantly decreased. The result showed that Citrulluslanatus and Persea Americana seeds extracts significantly and progressively lowered the glucose level, TC, TGs and LDL dose dependently while significantly causing a dose-related elevation in HDL concentration. The result shows that atorvastatin and the seeds extracts are capable of reducing risk of AI, CRI and CVRI in diabetic rats.

Keywords: Citrulluslanatus, Persea Americana, Phytochemicals, Antidiabetic, Dyslipidemia and lipoproteins.

Citation | Ukpabi.C.F; Minaseidiema.R.; Anyaogu.E.J; Njoku.C.I; Esihe.T.E (2020). Amelioration of Hyperglycemia and Dyslipidemia in Alloxan-Induced Diabetic Rats Using Citrulluslanatus and Persea Americana. Journal of Life Sciences Research, 7(1): 1-7. History:

Received: 7 October 2019

Revised: 13 November 2019

Accepted: 19 December 2019

Accepted: 19 December 2019

Published: 21 January 2020

Licensed: This work is licensed under a Creative Commons Attribution 3.0 License $($ oc)

Publisher: Asian Online Journal Publishing Group
Acknowledgement: All authors contributed to the conception and design of the study.

Funding: This study received no specific financial support.

Competing Interests: The authors declare that they have no conflict of interests.

Transparency: The authors confirm that the manuscript is an honest, accurate, and transparent account of the study was reported; that no vital features of the study have been omitted; and that any discrepancies from the features of the study have been omitted;
study as planned have been explained.

Ethical: This study follows all ethical practices during writing.

\section{Contents}

1. Introduction

2. Materials/Method

3. Result

4. Discussion

5. Conclusion

References... 


\section{Contribution of this paper to the literature}

In this study, it has been demonstrated that diabetes mellitus induced by alloxan monohydrate administration in albino rats cultivated hyperlipidemia. Subsequently, the hyperlipidemia resulted in dyslipidemia and was normalized by the oral administration of seeds extracts of Citrullus lanatus and Persea Americana.

\section{Introduction}

Many metabolic disturbances are associated with hyperglycemia in diabetic human [1]. Type 1 diabetes mellitus also called Insulin Dependent Diabetes Mellitus (IDDM) is a chronic condition in which the pancreas produces little or no insulin as a result of auto-immune disease. It typically appears in adolescence with more than 100 thousand cases per year in Nigeria [2]. Type 2 diabetes mellitus also called Non-Insulin Dependent Diabetes Mellitus (NIDDM) is a chronic condition that affects the way the body processes blood sugar (glucose). With type 2 diabetes, the body either doesn't produce enough insulin or it resists insulin. It is a very common disease in Nigeria with more than 1.5 million cases per year in adults [2].

The prevalence of diabetes mellitus in Nigeria has increased from 2.2\% as reported by Akinkugbe in 1997 from a national survey to $3.9 \%$ in 2025 as estimated by World Health Organization (WHO) [3].

The ability of insulin to mediate tissue glucose uptake and influence glucose and lipid metabolic enzymes are major factors of glucose balance. Metabolic disturbances are apparent as lipoprotein lipase is activated by insulin, therefore insulin resistance or insulin deficiency may result in extremely elevated triglyceride levels [4, 5].

Similarly, cholesterylester hydrolase within adipocytes is inhibited by insulin (this hydrolysis triglycerides to produce NEFA and glycerol) [6]. Therefore in insulin deficiency or resistance increased levels of Non-Esterified Fatty Acids (NEFA) are releases from the adipocytes. Hence, there will be lowered levels of triglyceride clearance as a result of reduced activation of lipoprotein lipase [6]. Consequently, diabetes is accompanied with increased glycogenolysis, lipolysis and gluconeogenesis and these biochemical activities result in hyperlipidemia. An elevation of blood cholesterol low density lipoprotein (LDL) and triglycerides levels with low level of high density lipoprotein (HDL) is a major indicator of dyslipidemia which chronically leads to the increase of cardiovascular disease (CVD) [7]. This literature is in line with a study done in Nigeria, where dyslipidemia was found to be highly prevalent in $90.7 \%$ of patients attending the medical outpatients clinics, diabetic clinic or admitted into the medical wards of hospital were recruited over a period of 12 months [8]. Although, several factors account for increased CVD risk diabetes, abnormalities of lipid metabolism are important contributors [9, 10].

The impact of CVD in industrialized countries as the leading cause of death in men and women is well documented $[8,11,12]$. The current environmental adaptation toward urbanization and changes in lifestyle could be responsible for the rising prevalence of obesity which has been linked with lipid abnormalities in Africans [13].

In animal studies, several investigations have used alloxan monohydrate-injected diabetic rats( a model of type 1 diabetes) to examine the effects of medicinal plants on hyperlipidemia [14]. Alloxan monohydrate used in reduced concentrations may cause decreased insulin secretion producing a decreased body tissue utilization of glucose and creating an environment for regeneration process of the pancreatic gland [5].

Most of these studies have shown that the rise in blood sugar was accompanied by marked increase in cholesterol, triglycerides, LDL and reduction in HDL. Furthermore, these studies showed dose-dependent response where low-doses had low responses and high-doses had high responses, thus reducing coronary risk index (CRI) and cardiovascular risk index (CVRI).

Hence, in addition to controlling hyperglycemia, treatment of dyslipidemia is inevitable to reduce CVD events in diabetes [15]. While the normalizing drugs employed for the treatment of dyslipidemia are effective, these drugs are not easily affordable to many patients [16]. In addition, the use of some of these drugs is associated with undesirable side effects. These factors compel patients to seek alternative and complementary medicines. Therapeutically, medicinal plants have many properties such as the effectiveness, safety and low cost for many diseases. Remedies from natural products maybe effective and safe alternative treatment for DM and its co morbidities, The potential impact of medicinal plants must be first proven in suitable animal models.

Two [2] of such complementary medicinal plants that have gained wide attention in the past are watermelon (CitrullusLanatus) seeds and avocado (Persea Americana) seeds. Watermelon (Citrulluslanatus) is a plant species in the family cucurbitaceae, it contains magnesium which helps to regulate blood pressure and the metabolism of carbohydrates which has a beneficial effect on blood sugar level. Avocado (Perseaamericana) is a tree from the family of lauraceae. It extracts may help to reduce blood pressure, a key risk factor for heart disease. This has necessitated exploration and screening of medicinal plants with acclaimed therapeutic efficacies in diabetes mellitus management. Therefore, the objective of this research is to investigate the Amelioration of hyperglycemica and dyslipidemia in Alloxan-induced rats using watermelon and avocado seeds on the laboratory induced rats. In doing so, we will attain to provide the pharmacological evidence for their therapeutic usage.

\section{Materials/Method}

\subsection{Materials and Drugs}

Insulin (Novolog USA) is an anti-diabetic drug and was used as test drug.Atorvastatin (Unipex USA) is a lipid lowering drug and may reduce both LDL cholesterol and TGs through reduction of VLDL.

Vitamin C ( Emzor ltd Nigeria) is a L-ascorbic acid, anti-oxidant and anti-inflammatory.

\subsection{Reagents/Chemical Utilized}

Alloxan monohydrate (St. Louis, MD USA) cholesterol reagent (Teco Diagnostics, USA) Triglyceride lipo reagent (Teco Diagnostics, USA) and HDL cholesterol reagent (Agape Diagnostics, Switzerland).

\subsection{Samples}

Fresh samples of watermelon and avocado pea seeds ( Umugasimarket,Aba Nigeria). 


\subsection{Experimental Protocol}

Normal and healthy albino rats ( male and female) of winstar strain ( 2-3 months) 120-200g were collected from the animal house of Department of Biochemistry, University of Port Harcourt, Nigeria. The animals were allowed to acclimatize for one week in the Department of Biochemistry, Abia State Polytechnic, Aba. They were kept in different ages with high hygiene and of standard housing conditions of temperature $(22-28 \mathrm{c})$ and 12 hours light/ 12 hours dark regime. They were fed with standard rat feed and water libitum throughout the duration of the study.

\subsection{Sample Preparation}

Healthy seeds of citrulluslanatus and persea Americana were collected, washed properly under running water and air dried at room temperature for several days. The dried seeds were then pulverized using an electric blender and stored in an air- tight container and kept in a cool-dry place for further analysis.

A mass of $50 \mathrm{~g}$ of the powdered seeds was weighed and dissolved in $400 \mathrm{ml}$ of hot distilled water of temperature (40c-60c) and allowed to cool for 60minutes and was filtered before being used in administration. These aqueous extracts were prepared daily to avoid turbidity and bacteria actions due to poor storage systems.

\subsection{Phytochemical Screening}

Phytochemical screenings of citrulluslanatus seeds and persea Americana seeds were carried out to detect the presence of Alkaloids, Tannins, Flavonoids and Saponins following the standards methods given in Verma, et al. $[17]$.

\subsection{Experimental Design}

Table-1. Grouping of animals and treatment model.

\begin{tabular}{c|l|l}
\hline Groups & Name & \multicolumn{1}{|c}{ Treatment } \\
\hline $\mathrm{A}$ & Normal control & Normal rats, given food and water \\
\hline $\mathrm{B}$ & Diabetic control orNegative control & Diabetic rats, received standard pelletdiet and water libitum \\
\hline $\mathrm{C}$ & Diabetic standard:Insulin & $\begin{array}{l}\text { Diabetic rats were treated with referencestandard insulin } \\
40 \mathrm{mg} / \mathrm{kg})\end{array}$ \\
\hline $\mathrm{D}$ & Lipidemic standard:Astorvastatin & $\begin{array}{l}\text { Diabetic rats were treated with reference standard } \\
\text { Astorvastatin ( } 30 \mathrm{mg} / \mathrm{kg})\end{array}$ \\
\hline $\mathrm{E}_{1}$ & Herbal Test:AVS-LD & $\begin{array}{l}\text { Diabetic rats were treated with Avocado seed at minimum } \\
\text { (200mg/ } / \mathrm{kg} \text { of rat body) Dose }\end{array}$ \\
\hline $\mathrm{E}_{2}$ & Herbal Test:AVS-HD & $\begin{array}{l}\text { Diabetic rats were treated with Avocado seed at maximum }( \\
400 \mathrm{mg} / \mathrm{kg} \text { of rat body)Dose }\end{array}$ \\
\hline $\mathrm{F}_{1}$ & Herbal Test: WMS-LD & $\begin{array}{l}\text { Diabetic rats were treated with watermelon seed at minimum } \\
\text { 200mg/kg) Dose }\end{array}$ \\
\hline $\mathrm{F}_{2}$ & Herbal Test: WMS-HD & $\begin{array}{l}\text { Diabetic rats were treated with watermelon seed at maximum } \\
(400 \mathrm{mg} / \mathrm{kg} \text { of rat body) Dose }\end{array}$ \\
\hline
\end{tabular}

\subsection{Induction of Diabetes}

The procedure for induction of diabetes has been observed. The animals of group B,D,E and $\mathrm{F}$ were weighed and fasted overnight before given of alloxan monohydrate diabetes was induced by single dose of alloxan monohydrate $100 \mathrm{mg} / \mathrm{kg}$ injected intrapertioneally. The fasting blood glucose was measured on the $3^{\text {rd }}$ day after alloxan monohydrate injection by glucometer to ensure induction of diabetes. Rats with blood glucose levels $>250 \mathrm{mg} / \mathrm{dl}$ are considered as diabetic and included in study [18].

Subsequently, treatment regimes of hyperglycemia started on the $6^{\text {th }}, 9^{\text {th }}$ and $12^{\text {th }}$ day of the experiment respectively.

\subsection{Biochemical Analysis}

\subsubsection{Collection of Blood Samples}

After given the sample, the animals were fasted for 24 hours. Blood was collected by cardiac puncture into clean tubes and was later centrifuged at 3000rpm for 10minutes using a centrifuge to remove cells and recover serum for biochemical assay.

\subsection{Glucose Estimation}

Glucose is a major carbohydrate present in the blood and serves as a primary source of energy. Glucose oxidase is an enzyme highly specific for glucose. It catalyses the oxidase is an enzyme highly specific for glucose. It catalyses the oxidation of Beta D-glucose present in the plasma to D glucono-1,5-lactone with the formation of hydrogen peroxide. The lactone is then slowly hydrolyzed to D-gluconic acid. In the presence of the enzyme peroxidase, the hydrogen peroxidase is broken down and oxygen released reacts with 4-amino-phenazone and phenol to give a pink colour. The absorbance of the colour produced is measured in a spectrophotometer.

\subsection{Lipid Profile Analysis}

The plasma total cholesterol (TC), Triglycerides (TG) and HDL (High Density Lipoprotein) were measured using commercial kits, via enzyme coupled reactions and the coloured complex, measured by spectrophotometry. LDL (Low Density Lipoprotein) was calculated using Friedwald's equation [5].

Determination of Atherogenic Index (AI), Coronary Risk Index (CRI), and Cardiovascular Risk Index ( CVRI) The AI, CRI and CVRI were calculated using the formulae [9, 19, 20]. 
$\mathrm{AI}=\underline{\mathrm{LDL} \text { Cholesterol }}$

HDL Cholesterol

$\mathrm{CRI}=\underline{\mathrm{TC}}$

HDL Cholesterol

CVRI $=\underline{\text { TGs }}$

HDL Cholesterol

\subsection{Statistical Analysis}

Results from the analysis were expressed as Mean $+\mathrm{SD}$ and $\mathrm{P}<0.05$ being considered as statistical significant.

\section{Result}

3.1. Phytochemical Screenig of the Various Seeds Extracts

Phytochemical composition of aqueous seeds extract of Citrulluslanatus and Perseaamericana The results obtained from the phytochemical analysis showed that the aqueous extract of Citrulluslanatus and Perseaamericana gave positive reactions for Alkaloids,tannins, flavonoids and saponins. Alkaloids reactions showed the deepest colouration in citrulluslanatus and moderate level in Perseaamericana while saponins showed the deepest colouration in both herbs.

Table-2. Phytochemical screenig of the various seeds extracts.

\begin{tabular}{c|l|c|c}
\hline Phytochemical constituents & \multicolumn{1}{|l|}{ Test } & \multicolumn{2}{c}{ Qualitative Abundance } \\
\cline { 3 - 4 } & & Citrulluslanatus & Persea Americana \\
\hline Alkaloids & a. Mayers test & +++ & ++ \\
& b. Murexide test & +++ & ++ \\
\hline Tannins & a. 5\% Fecl3 & ++ & + \\
\hline Flavonoids & b. Dilute HNO3 & ++ & ++ \\
& a. Lead acetate & + & +++ \\
\hline Saponins & b. Sodium hydroxide & +++ & +++ \\
\hline
\end{tabular}

Serum Glucose Concentrations of Alloxan Induced Albino Rats Following Oral Administration of Aqueous Seeds extracts of Citrulluslanatus and Persea Americana.

Table 3 Showed that Alloxan caused significant $(\mathrm{P}>0.05)$ increase in the glucose level in the Albino rats. WMS, AVS and Insulin treatments showed improvement in the diabetic rats by reducing the blood glucose level. It was observed that WMS has the most curative effect against increment in glucose at low dose.

Table-3. Serum Glucose Concentrations of alloxan induced albino rats following oral administration of aqueous seeds extracts of Citrulluslanatus and Persea Americana.

\begin{tabular}{|c|c|c|c|c|}
\hline Group & $\begin{array}{l}\text { Initial glucose } \\
\text { Conc. }(\mathrm{mg} / \mathrm{dl})\end{array}$ & $\begin{array}{l}\text { Glucose conc. } \\
\text { After } 6 \text { days of } \\
\text { treatment }(\mathrm{mg} / \mathrm{dl})\end{array}$ & $\begin{array}{c}\text { Glucose } \\
\text { After 9days of } \\
\text { treatment }(\mathrm{mg} / \mathrm{dl})\end{array}$ & $\begin{array}{c}\text { Glucose } \\
\text { After 12days of } \\
\text { treatment }(\mathrm{mg} / \mathrm{dl})\end{array}$ \\
\hline A & $83.00 \pm 2.30$ & $83.40 \pm 3.20$ & $84.00 \pm 1.98$ & $85.50 \pm 2.91$ \\
\hline $\mathrm{B}$ & $283.33 \pm 1.34$ & $268.58 \pm 1.64$ & $271.23 \pm 1.15$ & $266.85 \pm 3.00$ \\
\hline $\mathrm{C}$ & $280.00 \pm 1.34$ & $210.25 \pm 2.96$ & $160.12 \pm 1.33$ & $100.13 \pm 1.91$ \\
\hline $\mathrm{E}_{1}(\mathrm{AVS}-\mathrm{LD})$ & $290.00 \pm 4.44$ & $220.55 \pm 2.70$ & $160.00 \pm 1.60$ & $108.00 \pm 1.55$ \\
\hline $\mathrm{E}_{2}(\mathrm{AVS}-\mathrm{HD})$ & $280.00 \pm 2.60$ & $209.60 \pm 2.88$ & $180.00 \pm 2.06$ & $90.00 \pm 4.60$ \\
\hline $\mathrm{F}_{1} \quad(\mathrm{WMS}-\mathrm{LD})$ & $290.00 \pm 4.44$ & $127.09 \pm 9.03$ & $118.75 \pm 8.33$ & $94.69 \pm 9.59$ \\
\hline $\mathrm{F}_{2}$ (WMS-HD) & $280.00 \pm 2.60$ & $92.72 \pm 2.08$ & $84.38 \pm 2.00$ & $71.88 \pm 2.67$ \\
\hline
\end{tabular}

Source: Experimental data.

3.2. Effect of Alloxan Monohydrate Induction on Lipid Profile of Albino Rats

The data displayed in Table 4 showed that alloxan caused significant increase in TC, TGs and LDL in the untreated diabetic rats. On the other hand HDL was significantly decreased.

Table-4.Effect of alloxan monohydrate induction on lipid profile of albino rats.

\begin{tabular}{c|c|c|c|c|c|c|c|c}
\hline $\begin{array}{c}\text { Lipid } \\
\text { profile }\end{array}$ & \multicolumn{2}{|c|}{ TC } & \multicolumn{2}{c|}{ TGs } & \multicolumn{3}{c}{ LDL } & \multicolumn{3}{c}{ HDL } \\
\hline GROUP & WMS & AVS & WMS & AVS & WMS & AVS & WMS & AVS \\
\hline NC & $80.51 \pm$ & $80.51 \pm 1$. & $81.87 \pm 1$. & $81.87 \pm 1$. & $28.82 \pm 1$. & $28.82 \pm 1$. & $36.64 \pm 2$. & $36.64 \pm 2$. \\
& 1.34 & 34 & 91 & 91 & 33 & 33 & 96 & 96 \\
\hline DC & $149.8 \pm$ & $149.8 \pm 1$. & $159.2 \pm 1$. & $159.2 \pm 1$. & $53.19 \pm 2$. & $53.19 \pm 2$. & $23.53 \pm 1$. & $23.53 \pm 1$. \\
& 1.41 & 41 & 51 & 51 & 67 & 67 & 59 & 59 \\
\hline
\end{tabular}

Source: Experimental data.

All values are expressed as the mean $\pm \mathrm{SD}(\mathrm{n}=5)$

NC: Normal Control, DC: Diabetic Control, TC: Total Cholesterol, TG: Triglycerides.

LDL: Low Density Lipoprotein, HDL: High Density Lipoprotein.

3.3. The Effect of Atorvastatin and the Various Seed-Extracts on TC, TGs, LDL AND HDL of the Diabetic Rats

Table 5 Showed that the treatment of diabetic rats with WMS, AVS and Atorvastatin caused significant $(\mathrm{p} \leq 0.05)$ decreased in TC, TG and LDL. On the other hand HDL was significantly increased.From Statistical 
Analysis the increase of TC level in rats that were treated with AVS was more than that in rats treated with WMS while the reverse was the case in TG.

Table-5. The effect of atorvastatin and the various seed-extracts on tc, tgs, ldl and hdl of the diabetic rats.

\begin{tabular}{c|c|c|c|c|c|c|c|c}
\hline $\begin{array}{c}\text { Lipid } \\
\text { profile }\end{array}$ & \multicolumn{3}{|c|}{ TC } & \multicolumn{2}{c|}{ TGs } & \multicolumn{2}{c}{ LDL } & \multicolumn{2}{c}{ HDL } \\
\hline Group & $13^{\text {th }}$ day & $18^{\text {th }}$ day & $13^{\text {th }}$ day & $18^{\text {th }}$ day & $13^{\text {th }}$ day & $18^{\text {th }}$ day & $13^{\text {th }}$ day & $18^{\text {th }}$ day \\
\hline AVT & $119.88 \pm$ & $89.23 \pm$ & $121.77 \pm$ & $82.38 \pm$ & $46.60 \pm$ & $29.40 \pm$ & $28.99 \pm$ & $37.48 \pm$ \\
& 3.12 & 2.42 & 3.88 & 2.84 & 0.95 & 2.03 & 1.59 & 4.56 \\
\hline AVS-LD & $140.02 \pm$ & $125.82 \pm$ & $150.32 \pm$ & $140.01 \pm$ & $47.87 \pm$ & $42.40 \pm$ & $28.02 \pm$ & $33.29 \pm$ \\
& 0.39 & 0.51 & 1.67 & 1.34 & 2.63 & 1.18 & 1.54 & 1.37 \\
\hline AVS-HD & $112.71 \pm$ & $88.6 \pm$ & $119.05 \pm$ & $89.24 \pm$ & $35.99 \pm$ & $27.09 \pm$ & $35.10 \pm$ & $42.24 \pm$ \\
& 0.04 & 3.32 & 2.47 & 2.86 & 0.93 & 1.16 & 0.63 & 4.32 \\
\hline WMS-LD & $135.00 \pm$ & $130.00 \pm$ & $146.32 \pm$ & $138.86 \pm$ & $48.90 \pm$ & $43.56 \pm$ & $25.00 \pm$ & $29.00 \pm$ \\
& 0.71 & 0.00 & 0.54 & 1.00 & 0.00 & 0.30 & 0.00 & 1.21 \\
\hline WMS-HD & $105.0 \pm$ & $92.65 \pm$ & $112.00 \pm$ & $88.89 \pm$ & $39.50 \pm$ & $30.20 \pm$ & $32.00 \pm$ & $45.54 \pm$ \\
& 0.71 & 2.01 & 0.70 & 2.56 & 0.71 & 0.93 & 0.00 & 2.47 \\
\hline
\end{tabular}

Source: Experimental data

All values are expressed as the mean $\pm \mathrm{SD}(\mathrm{n}=5)$

AVT: Atorvastatin, AVS-LD: Avocado Seed Low Dose

AVS-HD: Avocado Seed High Dose

WMS-LD: Watermelon Seed Low Dose

WMS-HD: Watermelon Seed High Dose.

3.4. Effects of the Various Seed-Extracts on Ai, Cri and Cori of Diabetic Rats

The result shows that AVT, WMS and AVS are capable of reducing risk of AI, CRI and CVRI in diabetic rats. AVT treatment had the most reduction, followed by WMS and AVS treatments.

Table-6 .Effects of the various seeds extracts on ai, cri and cvri of diabetic rats.

\begin{tabular}{c|c|c|c|c|c|c}
\hline Lipid profile & \multicolumn{2}{|c|}{ AI } & \multicolumn{2}{c|}{ CRI } & \multicolumn{2}{c}{ CVRI } \\
\hline Group & $13^{\text {th }}$ Day & $18^{\text {th }}$ Day & $13^{\text {th }}$ Day & $18^{\text {th }}$ Day & $13^{\text {th }}$ Day & $18^{\text {th }}$ Day \\
\hline AVT & 1.607 & 0.784 & 4.135 & 2.380 & 4.200 & 2.197 \\
\hline WMS-LD & 1.956 & 1.502 & 5.4 & 4.482 & 5.852 & 4.788 \\
\hline WMS-HD & 1.234 & 0.663 & 3.281 & 2.034 & 3.5 & 1.951 \\
\hline AVS-LD & 1.708 & 1.273 & 4.997 & 3.779 & 5.364 & 4.205 \\
\hline AVS-HD & 1.025 & 0.641 & 3.211 & 2.098 & 3.391 & 2.112 \\
\hline
\end{tabular}

Source: Experimental data.

All values are expressed as the mean $\pm \mathrm{SD}(\mathrm{n}=5)$.

AVT: Atorvastatin.

WMS-LD: Watermelon Seed Low Dose, WMS-HD: Watermelon Seed High Dose.

AVS-LD: Avocado Seed Low Dose, AVS-HD: Avocado Seed High Dose.

\section{Discussion}

Citrulluslanatus and Persea Americana are traditionally used in folk medicine for combating various diseases. This therapeutic action is attributed to the presence of phytochemical compounds, which are related to the prevention of many diseases. There are important secondary metabolites synthesized in plants during normal development and also in response to stress conditions.

In this study, the results from the phytochemical studies of Citrulluslanatus and Persea Americana indicated the presence of alkaloid, flavonoids, saponins and tannins in appreciable amount. These bioactive compounds possess biological properties such as anti-apoptosis, anti-aging, anti carcinogen, anti inflammation, anti atherosclerosis, cardiovascular protection and improvement of endothelial function as well as inhibition of angiogenesis and cell proliferation activities.

In this present study, rats treated with single dose of alloxan monohydrate developed pancreatic damage which was observed from hyperglycemic and subsequent dyslipidemic conditions. Two mechanisms that have been reported are the effect of ROS on the DNA of pancreatic islets and the disturbances in intracellular calcium homeostasis [3]. The fragmentation of DNA and elevation of cytosilic $\mathrm{Ca}^{2+}$ concentration in the beta cells exposed to alloxan have been noted. The use of lower dose alloxan $(100 \mathrm{mg} / \mathrm{kg})$ produced partial destruction of pancreatic beta cells giving the animal the opportunity to regenerate the surviving beta cells.

The present study shows that the seed extracts of Citrulluslanatus and Persea American significantly reduced the elevated blood glucose levels with respect to those of the diabetic control rats.

The two herb extracts produced significant reduction in blood glucose concentration when compared with the reference drug (Insulin). However, there was no significant difference in the glucose lowering effect. This antihyperglycemic action may be attributed to the potentiation of pancreatic mechanisms like enhanced transport of blood glucose to peripheral tissue, increased peripheral utilization of glucose via different enzymatic pathways or inhibition of intestinal absorption of glucose [21, 22].

Cholesterylester hydrolase is known to hydrolase triglycerides to free fatty acids and glycerol. Excess of fatty acids in plasma produced by the alloxan-induced diabetes promotes the liver conversion of some fatty acids into triglycerol and cholesterol which may be discharged into the blood as lipoproteins [23].

The present investigation showed high significant increase in plasma TC, TG and LDL in the diabetic rats while HDL level was reduced. The treatment with the seeds extracts resulted in decrease in plasma cholesterol, TG and LDL level with increase in HDL level. The dyslipidemia in the alloxan induced diabetic control rats was observed in the regulation of the activity of the cholesterylester hydrolase caused by the alloxan induced destruction of beta islets cells.

Similarly, the two herbs were able to normalize lipoprotein phenotype which was altered by the induction of alloxan monohydrate in the animals when compared with the reference drug (Atorvastatin). The results showed 
that total triglyceride, total cholesterol and low density lipoprotein in the alloxan monohydrate intoxicated rats were significantly reduced when compared to normal control whereas high density lipoprotein was increased.

Though, there was no significant difference in the lipid normalizing effect. Atorvastatin has been shown to reduce both LDL cholesterol and TGs through reduction of VLDL. T he increase in insulin secretion and the consequent decrease in blood glucose level may lead to stimulation of fatty acid biosynthesis( Insulin stimulates lipid synthesizing enzymes (fatty acid synthase, acetyl coA carboxylase) and also the incorporation of fatty acids into triglycerides in the liver and adipose tissue). The plasma concentration of lipoprotein (VLDL and LDL) will reduce since there is no elevated level of fatty acids (from lipolysis and from break down of triacylglycerol by the cholesterylester hydrolase) that will be converted to acetyl CoA in the liver. Elevated acetyl CoA are converted in the cholesterol, triacylglycerol and ketone bodies. The principal lipids carried by lipoprotein are triacylglycerol and cholesterol. Absence of elevated cholesterol and triacylglycerol in the liver will lead to decreased synthesis of VLDL[23].

Conventionally, normalization of lipoprotein phenotype by the two herbs extracts could point to their potential to reduce cardiovascular disease risk. It is well known that LDL/HDL, TC/HDL and TGs/HDL ratios are all independent and significant predictors of AI, CRI and CVRI respectively. The study shows that Atorvastatin had $0.78,2.38$ and 2.19 for $\mathrm{AI}, \mathrm{CRI}$ and CVRI respectively.

WMS had 1.50, 4.48 and 4.78 for AI, CRI and CVRI respectively. Finally, AVS had 1.27, 3.77 and 4.20 for AI, CRI and CVRI respectively. Thus, there was significance difference between Atorvastatin and the two herbs at low dose.

\section{Conclusion}

Normalization of lipoprotein phenotype by the two herbs extracts could point to their potential to reduce cardiovascular disease risk. The present study shows that the seeds extracts of Citrullus lanatus and persea Americana significantly reduced the elevated blood glucose levels with respect to those of the diabetic control rats. Secondly total triglyceride, total cholesterol and low density lipoprotein in the alloxan monohydrate intoxicated rats were significantly reduced when compared to normal control whereas high density lipoprotein was increased. Therefore, in addition to controlling hyperglycemia, treatment of dyslipidemia is inevitable to reduced CVD events in diabetes.

\section{References}

[1] J. John, "Evaluation of hypoglycemic effect of aloe vera on allaxon induced diabetic rats," International Journal of Information Research and Review, vol. 4, pp. 3865-3868, 2017.

[2] R. N. Oputa and S. Chinenye, "Diabetes in Nigeria a translational medicine approach," African Journal of Diabetes Medicine, vol. 23, pp. 7-9, 2015.

[3] C. F. Ukpabi, M. N. Chukwu, J. N. Onyemaechi, P. Ibe, and E. F. Onuh, "Anti diabetic and Anti hyperlipidemic effects of aqueous extract of carica papaya leaf on the experimental model against single alloxan toxicity," World Scientific Research, vol. 6, pp. 14-18, 2019.Available at: https://doi.org/10.20448/journal.510.2019.61.14.18.

[4] C. F. Ukpabi, S. Amanoh, T. E. Esihe, O. K. Ndukwe, and M. N. Chukwu, "Effect of aqueous seed extract of Garcinia Kola (Bitter Kola) on diabetic hyperlipidemia profile in Alloxan induced diabetic rats," Journal of Biotechnological Research, vol. 3, pp. 1-7, 2019.

C. Ukpabi, J. Nwankwo, T. Eshie, and J. Isu, "Extract of vernonia amygdalina on blood glucose and lipid profile of alloxan-induced diabetic rats," IOSR Journal of Pharmacy and Biological Sciences, vol. 13, pp. 13-17, 2018.

[6] G. C. Zubay, W. W. Parson, and D. E. Vance, Principles of biochemistry WMC. USA: Brown Publishers, 1995.

A. Al-Attar, "Physiological effects of some plant oils supplementation on streptozotocin-induced diabetic rats," Research Journal of Medicine and Medical Sciences, vol. 5, pp. 55-71, 2010.

[8] N. N. Jisieke-Onuigbo, E. I. Unuigbe, and Oguejiofor, "Dyslipidemias in type 2diabetes mellitus patients in Nnewi South -East Nigeria," Annals of African Medicine, vol. 10, pp. 285-289, 2011.

[9] O. Erejuwa, N. Nwobodo, J. Akpan, U. Okorie, C. Ezeonu, B. Ezeokpo, K. Nwadike, E. Erhiano, M. W. Abdul, and S. Sulaiman, "Nigerian honey ameliorates hyperglycemia and dyslipidemia in alloxan-induced diabetic rats," Nutrients, vol. 8, pp. 95-95, 2016.

[10] E. Susanti, M. Donosepoetro, I. Patellongi, and M. Arif, "Differences between several atherogenic parameters in patients with controlled and uncontrolled type 2 Diabetes Mellitus," Medical Journal of Indonesia, vol. 19, pp. 103-108, 2010.

[11] C. M. Ballantyne, S. M. Grundy, A. Oberman, R. Kreisberg, R. Havel, P. Frost, and S. Haffner, "Hyperlipidemia: Diagnostic and therapeutic perspectives," Journal of Clinical Endocrinology and Metabolism, vol. 85, pp. 2089-2112, 2000.

[12] P. Gunby, "Cardiovascular diseases remain nation's leading cause of death," JAMA, vol. 267, pp. 335-336, 1992.Available at: https://doi.org/10.1001/jama.267.3.335.

[13] M. A. Njelekela, H. Negishi, Y. Nara, T. Sato, M. Tomohiro, S. Kuga, T. Noguchi, T. Kanda, M. Yamori, and Y. Matshalla, "Obesity and lipid profiles in middle aged men and women in Tanzania," East African Medical Journal, vol. 79, pp. 58-64, 2002.Available at: https://doi.org/10.4314/eamj.v79i2.8901.

[14] R. H. Tuhin, M. Begum, S. Rahman, R. Karm, T. Begum, S. U. Ahmed, R. Mostota, A. Hossan, M. Abdel-Daim, and R. Begum, "Wound healing effect of Euphorbia hirta linn. (Euphorbiaceace) in alloxan induced diabetic rats," BMC Complementary and Alternative Medicine, vol. 17, pp. 423-437, 2017.Available at: https://doi.org/10.1186/s12906-017-1930-x.

[15] C. M. Ballantyne, "Treatment of dyslipidemia to reduce cardiovascular risk in patients with multiple risk factors," Clin Cornerstone, vol. 8, pp. 6-13, 2007.Available at: https://doi.org/10.1016/s1098-3597(07)80010-x.

[16] J. Williams, W. Steers, S. Ettner, C. Mangione, and O. Duru, "Cost-related nonadherence by medication type among medicare part D beneficiaries with diabetes," Medical Care, vol. 51, pp. 193-198, 2013.Available at: https://doi.org/10.1097/mlr.obo13e318270dc52.

[17] S. K. Verma, S. Rani, K. S., I. Dhamija, S. Sharma, and A. K. Sharma, "Pharmacological evaluation of indigenous antiurolithiatic formulation neeri (NRT-RF)," Advanced Biomedical Bulletin, vol. 3, pp. 41-57, 2015.

[18] M. Jesza-Skowron, E. Flaczyk, J. Jeszka, K. Z., E. Krol, and M. S. Buchowski, "Mulberry leaf extract intake reduces hyperglycemia in streptozotocin (STZ)-induced diabetic rats fed high- fat diet," Journal of Functional Foods, vol. 8, pp. 9-17, 2014.Available at: https://doi.org/10.1016/j.jff.2014.02.018.

[19] R. D. Abbott, P. Wilson, W. B. Kannel, and W. P. Castelli, "High density lipoprotein cholesterol, total cholesterol screening, and myocardial infarction. The Framingham study," Arteriosclerosis: An Official Journal of the American Heart Association, Inc, vol. 8, pp. 207-211, 1988.Available at: https://doi.org/10.1161/01.atv.8.3.207.

[20] S. Alladi, A. Khada, and M. Shanmugan, "Induction of hypercholesterolemia by supplementing soy protein with acetate generating amino acids," Nutrition Reports International, vol. 40, pp. 893-894, 1989.

[21] I. Larner, A. G. Gilman, L. S. Goodman, and A. Gilman, Insulin and oral hypoglycemic drugs: Glucagon in pharmacological basis of therapeutics, 7th ed. London: Macmillian, 1985. 
[22] G. O. Igile, W. Oleszek, M. Jurzysta, S. Burda, M. Fafunso, and A. A. Fasanmade, "Flavonoids from Vernonia amygdalina and their antioxidant activities," Journal of Agricultural and Food Chemistry, vol. 42, pp. 2445-2448, 1994.Available at: https://doi.org/10.1021/jfoo047a015.

[23] K. N. Bopanna, I. Kanna, G. Sushma, R. Balaraman, and S. P. Rathod, "Antidiabetic and anti hyper lipidaemic effects of neem seed kernel powder on alloxan diabetic rabbits," Indian Journal of Pharmacology, vol. 29, pp. 162-167, 1997. 